\title{
A sistematização do campo da antropologia jurídica
}

\author{
The systematization of legal anthropology field
}

Lívia Dias Pinto Vitenti ${ }^{1}$

Resumo: Meu propósito no presente artigo é o de cumprir com o reconhecimento da prática antropológica jurídica, desde seus clássicos até alguns debates considerados contemporâneos, como os apresentados por Clifford Geertz e Jane Collier. Para tanto, neste trabalho realizo uma revisão bibliográfica de alguns trabalhos já produzidos no campo da Antropologia Jurídica, oferecendo ao mesmo tempo ao leitor uma leitura crítica das teorias.

Palavras-chave: antropologia jurídica, sistemas legais, direito, antropologia

Abstract: My purpose in this article is to compile the knowledge about Legal Anthropology, from the classics to some current debate, as those presented by Clifford Geertz and Jane Collier. Therefore, in this work I carry out a bibliographical revision of some produced works in the field of Legal Anthropology, offering at the same time a theories' critical understanding.

Keywords: legal anthropology, legal systems, law, anthropology

\section{Introdução}

\footnotetext{
${ }^{1}$ Universidade de Brasília, Professora substituta, departamento de Antropologia. Email: lvitenti@yahoo.com.br.
}

Latitude, Vol. 9, n², pp. 07-28, 2015

DOI: https://doi.org/10.28998/2179-5428.20150204 
A sistematização do campo da antropologia jurídica

Trabalharei no presente artigo as afinidades e as discordâncias que se apresentam entre a Antropologia e o Direito. As analisarei uma vez que constituem um material rico que possibilita investigações mais acuradas acerca dos sistemas legais ou de direito. Ao pensar na história de tal relação, o que detecto é o interesse de muitos juristas pelo campo investigativo da Antropologia. Assim, apresentarei autores cruciais que, ao longo dos anos, contribuiram de forma essencial à formação do campo da Antropologia Jurídica.

\section{A emergência do campo da antropologia jurídica}

Optei por explanar brevemente alguns pontos pertinentes acerca dos autores Lewis Henry Morgan e sir Henry Sumner Maine que, no século XIX, transitaram com certa liberdade entre Antropologia e Direito, nos deixando um legado importante para a formação da Antropologia Jurídica. Sir Henry Sumner Maine, como primeiro exemplo, publicou em 1861 seu livro Ancient Law. Com o arcabouço dos estudos da jurisprudência e também pelo fato de ter atuado como governador britânico na Índia, Maine assentou bases para uma discussão muito em voga na Antropologia de sua época, a saber, a questão da evolução, da transformação social e do desenvolvimento. Tais questões foram investigadas a partir da comparação entre o parentesco e o status atribuído presentes nas sociedades tribais, e a territorialidade e o status adquirido na sociedade ocidental. Este autor conjuga sua análise acerca do Direito com a tendência geral de seu tempo. Ou seja, afirma que os princípios legais não existem nas sociedades consideradas primitivas, e o que opera como sistema de coerção é o apego rígido e automático aos costumes. Maine cunhou a expressão desde o status ao contrato, que se refere à subordinação total às regras de parentesco, as quais estão presentes nos sistemas sociais não ocidentais. Neste contexto, o sujeito era posicionado socialmente de acordo com seu status de parentesco, de tal forma que seus direitos e deveres estavam condicionados à prescrição dos costumes (Pospísil, 1974).

Em 1870, o então advogado estadunidense Lewis Henry Morgan publicou um livro intitulado Systems of Consanguinity and Affinity of the Human Family. Embora este livro já verse sobre aspectos pertinentes aos sistemas de 
direito, é no seu livro Ancient Society, de 1887, que se pode encontrar sua real contribuição à Antropologia como um todo e em particular ao estudo da Antropologia do Direito. Brevemente, outro autor que merece atenção é Émile Durkheim, que também pode ser associado à linha que enfatiza a rigidez consuetudinária, justamente por suas colocações acerca da solidariedade mecânica. Sendo assim, uma vez que a comunidade, enquanto homogênea, compartilha crenças e valores, as regras são mantidas de forma que qualquer resistência ou qualquer ação que as infrinja são consideradas como afrontas a toda comunidade e devem sofrer severas punições (Pospísil, 1974).

Os autores citados e outros tantos precursores dos estudos do campo da Antropologia Jurídica afirmavam, sem hesitação, que os povos considerados primitivos eram movidos pela subordinação rígida e automática aos costumes, ao mesmo tempo em que qualquer falta ou infração era tomada como um atentado contra a totalidade dos costumes. Este cenário persistiu até o começo do século XX, quando, em 1926, Bronislaw Malinowski publica seu livro Crime e Costume na Sociedade Selvagem.

\section{Bronislaw Malinowski}

De seu largo e detalhado Os Argonautas do Pacífico Ocidentalde 1922, nasce o pequeno, porém importante, Crime e Costume na Sociedade Selvagem. Logo no prefácio de 1926, Malinowski afirma que o estudo antropológico da jurisprudência carecia de teoria, sobretudo daquela que surge do contato real com os grupos que até então eram considerados primitivos. Ele enfatiza a necessidade de se examinar a questão da lei primitiva e das forças coercitivas destinadas à manutenção da ordem, da uniformidade e da coesão de um grupo primitivo e considera que importantes teorias antropológicas acerca da organização social tribal estariam melhor embasadas se considerassem os mecanismos de preservação da ordem nas sociedades em questão.

Ainda no prefácio, Malinowski afirma que o conhecimento acima exposto poderia auxiliar os administradores coloniais. Ou seja, com base no conhecimento das leis, pode-se verificar a existência de uma lei firme e de uma tradição rigorosa, que respondem a demandas biológicas, mentais e sociais que 
A sistematização do campo da antropologia jurídica

são inerentes ao ser humano em qualquer sociedade. Este autor postula que a organização da vida tribal estava permanentemente influenciada pela lei e pela ordem, as quais eram senhoras da cotidianidade e dos atos de importância pública. Para Malinowski, seus colegas antropólogos eram completamente indiferentes à justiça considerada selvagem e aos seus métodos de controle social. Contudo, me parece interessante ressaltar que este autor afirma que esta falha presente nas teorias antropológicas de sua época se devia a uma ideia romantizada de uma suposta perfeição da legalidade primitiva.

A primeira argumentação de Malinowski se refere à submissão automática aos costumes. Sendo assim, afirma que a principal falha da teoria antropológica se localizava na tentativa de transmutar a ideia de total ausência de regras para seu extremo oposto.Ou seja, de pensar que o nativo era totalmente obediente às leis, que não hesitava em se submeter automaticamente às regras de seu grupo e que, por isso, não lhes opunha maior resistência.

O selvagem - diz o veredito hodierno de competentes antropólogos - tem uma profunda reverência pela tradição e pelo costume, numa submissão automática às suas ordens. Ele obedece a elas servil, involuntáriae espontaneamente, por inércia mental, associada ao temor da opinião pública ou de castigo sobrenatural; ou por meio de um penetrante sentimento de grupo quando não instinto de grupo. (Malinowski, 2003, p. 15).

Assim Malinowski duvida que os grilhões da tradição, no âmbito das normas de comportamento, sejam os mesmos encontrados na arte, nas relações sociais, na indústria e na religião. Embora postule que qualquer obediência a tabus e regras sociais reconhecidas como desagradáveis ou opressivas só ocorreria à medida que o sujeito fosse compelido de modo irresistível a curvarse perante elas, entende que o axioma fundamental dos investigadores de seu tempo para a compreensão da ordem primitiva e da adesão à norma é 
justamente a ideia de total submissão às regras; e é discordando de tal axioma que formula sua crítica.

Malinowski aposta que, mesmo em sociedades onde não exista uma autoridade central, certas regras são cumpridas pela existência de um mecanismo de obrigação que é respaldado em motivos reais, interesses e sentimentos complexos. Por conseguinte, ao analisar a definição resumida da lei como um conjunto de regras impostas por uma autoridade independentemente de laços pessoais, este autor conclui que é uma maneira restrita que não contempla pontos relevantes no estudo do direito e da lei como, por exemplo, as normas de conduta que impelem o indivíduo a responder a obrigações para com outro indivíduo. Isso também pode ocorrer entre grupos. $\mathrm{O}$ sujeito então cumpre as regras porque reconhece a possibilidade de recompensa ou punição. E é a partir dessa visão tão abrangente da lei que este autor considera possível conhecer a natureza das forças que transformam uma lei em algo que deve ser respeitado e cumprido, obtendo resultados mais satisfatórios, sempre em contraposição a uma discussão, para ele pouco profícua, acerca dos problemas de autoridade, governo e punição.

O fato é que nenhuma sociedade pode funcionar eficientemente se as leis não forem obedecidas de modo voluntário e espontâneo. A ameaça de coerção e o medo da punição não afetam o homem comum, seja eleselvagem ou civilizado, enquanto, por outro lado, são indispensáveis em qualquer sociedade em relação a certos elementos turbulentos ou criminosos. Além disso, há um certo número de leis, tabus e obrigações emtoda cultura humana que muito pesa sobre todos os cidadãos, exigindogrande auto sacrifício, que é obedecido por razões morais, sentimentaise reais, embora sem qualquer espontaneidade (Malinowski, 2003, p. 17-18). 
A sistematização do campo da antropologia jurídica

O grande erro cometido pelos antropólogos, na opinião de Malinowski, é pressupor que, por não existirem analogias entre os sistemas de lei primitivos, que geralmente são de natureza complexa e difusa, e os sistemas de lei ocidentais, que estão baseados naordenação, na administração e no cumprimento da lei, os membros de uma sociedadeselvagem obedecem aos sistemas legais por uma misteriosa propensão. Segundo Malinowski seus contemporâneos não abordavam as questões psicológicas e sociais que estavam por detrás da obediência à tradição.

As regras da lei sobressaem ao resto porque são sentidas e consideradasobrigações de uma pessoa e justos direitos de outras. São sancionadas não por um simples motivo psicológico, mas por um mecanismo social definido de força compulsória, baseado, como sabemos, na dependência mútua e realizado no arranjo equivalente de serviços recíprocos e na combinação desses direitos em correntes de relacionamento múltiplo. A maneira cerimoniosa em que a maioria das transações é conduzida, acarretando crítica e controle público, aumenta ainda mais sua força compulsória (Malinowski, 2003, p. 47).

Assim, Malinowski considera que a compreensão da lei e das forças legais de um dado grupo social auxiliaria na descoberta e análise das regras dadas como obrigatórias, as quais, por sua vez, são ferramentas de entendimento acerca da natureza das forças coercitivas. Através desse método, se podem classificar normas e regras, entender como as mesmas são validadas e ainda compreender a lei primitiva e seus outros costumes, sem ideias préconcebidas.Sem um espírito de corpo, sem uma cumplicidade ou sentimento de comunidade seria impossível se manter uma ordem social. Contudo, estas características não são as que poderiam ser consideradas chave na organização social primitiva; ou seja, o então considerado selvagem foi visto por Malinowski como concomitantemente individualista e coletivista, como qualquer outro homem. Quando se aposta na total obediência e na absoluta 
rigidez do nativo perante as regras consuetudinárias, automaticamente se enfatiza a lei criminal de forma excessiva, o que leva à negação da possibilidade de lei civil.

De fato, o dogma da obediência automática, isto é, da absoluta rigidezdas regras do costume, implica uma ênfase excessiva da lei criminal nas comunidades primitivas e uma correspondente negação da possibilidade da lei civil. Regras absolutamente rígidas não podem ser expandidas ou adaptadas à vida, elas não precisam ser reforçadas - mas podem ser transgredidas (Malinowski, 2003, p. 47-48).

Em uma de suas discordâncias com Radcliffe-Brown, Malinowski rejeita a ideia de ausência de lei civil nas sociedades primitivas. Assim, discorda que o único aspecto legal detectável nas sociedades primitivas seja o crime e nega que os nativos desconheçam a lei civil e uma jurisprudência civil que possam ser alvo de estudos antropológicos. Ao contrário, entende que o estudo do mecanismo que controla a quebra de costumes pode ser caracterizado como específico para o estudo da jurisprudência tradicional.

Ao referir-se a seu campo especificamente, Malinowski afirma que a transgressão a mandamentos verdadeiros é penalizada, mas não punida, o que permite compreender que neste processo legal não há nenhum método inflexível além da linha que separa a lei civil da criminal. A lei civil se caracteriza por ser a lei formal utilizada como baliza para o conjunto de deveres e direitos individuais ou coletivos, respondidos por razões de reciprocidade ou exposição pública; as regras da lei civil são acessíveis. As leis e os fenômenos da lei não são instituições independentes. A lei faz parte da estrutura tribal e rege as obrigações às quais os nativos estão racionalmente subordinados e pode sofrer penalizações pela sua falta ou irresponsabilidade. As questões de lei não devem ser tratadas somente em termos de instituições localizadas com características legais. Inversamente, a lei deve ser entendida no próprio mecanismo social, o qual garante o cumprimento das obrigações e rege grande parte dos costumes de uma sociedade. 
A sistematização do campo da antropologia jurídica

Reiterando, Malinowski opõe-se ao que considerou ser o grande erro da Antropologia: afirmar que há uma força superior nas tradições e nos costumes, a qual conduz o nativo a suplantar desejos e inclinações pessoais automaticamente, de forma espontânea e involuntária. A lei existe justamente para coibir compulsões e espontaneidades, para compor um ambiente social baseado em concessões e sacrifícios. É claro que não se deve ignorar o poder de sanção da tradição, uma vez que esta faz parte do arranjo social, principalmente no que tange o cumprimento das regras de conduta, tanto no âmbito do público quanto no âmbito do privado. Contudo a tradição, por si só, não é um mecanismo capaz de conter automática e espontaneamente, ambições, desejos, enfim, aspectos de interesse individual.

Em toda e qualquer sociedade humana se podem detectar regras legais, a saber,conjuntos de regras práticas, que incômodas ou não, podem ser sancionadas ou ainda cumpridas por bom senso; e ainda conjuntos de regras consideradas demasiado vitais para serem violadas. E dando continuidade a este pensamento, Malinowski prognostica que se encontrarão na reciprocidade, na incidência sistemática, na exposição pública e na ambição os pontos relevantes para o funcionamento da lei primitiva.

Finalmente, Malinowski entende o conjunto de regras destinado a orientar a cooperação mútua e controlar a vida social como corpo de leis civis. Este por sua vez pode ser distinguido de outros conjuntos de regras de costumes, como os religiosos, os artesanais, os comerciais, entre outros. Estas outras regras se diferenciam das jurídicas uma vez que estas últimas se destacam por impor obrigações e direitos nos relacionamentos interpessoais. É importante ressaltar a força que Malinowski atribuiu aos castigos aos quais infratores são submetidos, tais como o escárnio público e o temor ao chefe. Estes, entre outros meios, considerando que não são os únicos, formam as principais forças de sanção presentes nas sociedades primitivas.

Malinowski entende lei civil como algo distinto à lei criminal. Assim, postulou que a lei obedecida, ou melhor, o direito civil, se traduz no conjunto de obrigações cumpridas forçosamente, as quais são, por vezes, reconhecidas como justas, embora sejam também reconhecidas como deveres. Seu cumprimento é assegurado por um meio que estabelece a reciprocidade e a opinião pública, as quais, por sua vez, são inerentes à estrutura da sociedade. 
Por outro lado, o direito criminal foi resumido como (...) as regras fundamentais que salvaguardam a vida, a propriedade e a personalidade.

Não há dúvida de que o costume não está baseado somente em uma força universal, indiferenciada, onipresente, numa inércia mental, embora indiscutivelmente exista e acrescente sua cota de influência a outra coerção. Deve haver em todas as sociedades uma categoria de regras suficientemente práticas para serem respaldadas por sanções religiosas, o bastante incômodas para serem deixadas para a simples boa vontade, por demais pessoalmente vitais para os indivíduos para serem impostas por qualquer organização abstrata. Esse é o domínio das regras legais, e atrevo-me a predizer que se descobrirá que a reciprocidade, a incidência sistemática, a publicidade e a ambição são os principais fatores no mecanismo da obrigação da lei primitiva (Malinowski, 2003, p. 55-56).

Finalmente, segundo Hoebel, em seu livro The Law of Primitive Man, o mérito de Malinowski, a respeito da teoria da lei na Antropologia, é o de ter estabelecido o direito como uma faceta da sociedade e cultura como um todo. A insistência na existência de brechas entre as normas ideais e a normas legais em uso também foi uma contribuição positiva. Outra contribuição foi o rompimento com a pretensa rigidez existente nos formalismos legais para a Antropologia, o que proporcionou um novo fôlego à Antropologia do Direito.

A. Radcliffe-Brown: o direito público e privado e suas sanções específicas

Foi a partir de seus estudos sobre os sistemas sociais primitivos que Radcliffe-Brown definiu os conceitos de papel e sanção, os quais o auxiliaram na compreensão da essência da vida legal em uma sociedade tribal. Este autor define papel como um aspecto da estrutura política da sociedade. Em qualquer 
A sistematização do campo da antropologia jurídica

estrutura social sempre haverá alguma diferenciação entre os papéis sociais de um sujeito em questão ou de um grupo de pessoas. A pessoa, ao atuar no campo econômico, religioso ou político, responde a papéis sociais alternativos. Nas sociedades primitivas, se identifica, segundo Radcliffe-Brown, pouco mais que uma diferenciação colocada em relação ao sexo e a idade; identifica-se, ainda, o reconhecimento não institucionalizado da autoridade ritual ou da autoridade advinda do êxito na guerra, na caça, na pesca, na cura, entre outros.

As sociedades ocidentais se diferenciam das sociedades primitivas porque apresentam uma maior distinção entre os indivíduos que a compõem e entre as classes sociais as quais os mesmos pertencem. A diferenciação observada entre sociedades primitivas e ocidentais pode ser notada também nas organizações políticas, uma vez que é nas mesmas que operam aqueles que respondem a papéis especiais da vida social, tais como os de juízes, reis e chefes. Assim, aquele que atua dentro de um desses ofícios está dotado da autoridade que lhe outorga privilégios, direitos e deveres. Costumes são os modos de conduta que se identificam em uma comunidade. Sanção é uma reação por parte da sociedade ou de considerável número de seus membros a um modo de conduta que é mediante ela sancionado (sanções positivas) ou desaprovado (sanções negativas) (Radcliffe-Brown, 1973, p. 252).

Radcliffe-Brown considerava que a distinção entre direito criminal e direito civil, tão utilizadas nas sociedades ocidentais, não deveria ser aplicada às sociedades primitivas. Afirmava que se deveria sim aplicar a distinção entre o direito de delitos públicos e o direito de delitos privados. Para este autor, em toda e qualquer sociedade uma ação será reconhecida como delito público se for, geralmente, motivo para a organização de um processo regular que pretenda ou consiga fixar determinada responsabilidade sobre um membro ou grupo de membros da sociedade; ou ainda que possa infligir punições, estas definidas pela sociedade ou pelos membros detentores de autoridade. Esta ação se denomina ação penal, e funciona a partir da necessidade de uma ação individual ou coletiva que contrarie algum forte e definido sentimento moral, ocasionando o desarranjo social. A sanção penal é entendida como o mecanismo de manutenção da moral; funciona no sentido de manter, utilizando uma coerção necessária, uma moral compartilhada coletivamente. 
Em uma segunda definição de sanções, Radcliffe-Brown postula que estas podem ser difusas ou organizadas, sendo que as primeiras são expressões espontâneas de aprovação ou desaprovação pelos membros da comunidade atuando como indivíduos, enquanto que as últimas são sanções sociais executadas de acordo com algum procedimento tradicional reconhecido.

As sanções vigentes numa comunidade constituem no indivíduo móveis para regulação de sua conduta de conformidade com o costume. São eficazes, em primeiro lugar, pelo desejo do indivíduo de obter aprovação e evitar desaprovação de seus companheiros, obter recompensas ou evitar castigos que a comunidade oferece ou com que ameaça; e, em segundo lugar, pelo fato de que o indivíduo aprende a reagir a determinados modos de conduta com julgamentos de aprovação ou desaprovação do mesmo modo que seus companheiros, e, portanto avalia sua própria conduta tanto prevendo como reconstituindo pelos padrões que se adaptam mais ou menos intimamente com os vigentes na comunidade a que pertence. $\mathrm{O}$ que se chama consciência é, pois, no sentido mais amplo, o reflexo no indivíduo das sanções da sociedade (Radcliffe-Brown, 1973, p. 252-253).

Radcliffe-Brown define uma série de tipos de sanções, que podem ser divididas em: negativas difusas, que tornam o culpado sujeito a reprovação de seus iguais; sanções religiosas ou sobrenaturais e místicas - que são difusas que causam ao culpado uma condição de impureza ritual que constitui perigo para si mesmo e para aqueles com quem está em contato; sanções organizadas, que são entendidas como uma evolução especial das sanções difusas; as sanções penais, pelas quais a comunidade, através de certas pessoas na qualidade de autoridades judiciais constituídas, impõem castigos que podem ser considerados expressões coletivas da indignação moral ocasionada pela ação do indivíduo, meios de eliminar a contaminação ritual pela imposição de 
A sistematização do campo da antropologia jurídica

expiação ao culpado, ou ainda ambas as coisas. Existem ainda as sanções negativas organizadas e as sanções sociais primárias e secundárias.

As sanções negativas organizadas, em particular, e em grande grau as sanções secundárias, são expressões de uma condição de disforia social ensejada por algum fato. A função da sanção é restaurar a euforia social ao oferecer expressão coletiva definida aos sentimentos que foram afetados pelo feito, como nas sanções primárias e em certo grau nas sanções secundárias, ou pela remoção de um conflito no seio da própria comunidade (Radcliffe-Brown, 1973, p. 259).

Quando há uma formação legal que inclua árbitros e juízes reconhecidos para sancionar um delito, isso significa que só falta a presença de uma autoridade legal que legitime o que é proferido pelos juízes. Essa descrição se refere aos pressupostos acerca do surgimento de um sistema legal destinado a julgar delitos privados. Na opinião de Radcliffe-Brown, trata-se uma linha evolutiva, uma vez que partem da arbitragem acerca dos costumes e chegam a tribunais regulares, o que proporciona à sociedade a possibilidade de atribuir força de lei aos julgamentos.

Radcliffe-Brown diferencia a análise acerca dos direitos de delitos privados e de delitos públicos. Assim, afirma que quando há conflito entre pessoas ou grupos de pessoas, e isto é levado a corte para julgamento, trata-se de direito de delitos privados; quando a transgressão é penalizada diretamente pela autoridade central, trata-se de direito de delitos públicos. Ao se referir ao moderno direito civil, assevera que o mesmo decorre dos direitos de delitos privados, assim como o moderno direito criminal decorre dos direitos de delitos públicos. Contudo, há variações nas sociedades primitivas, e em muitos casos o que é considerado pelo ocidente como delitos públicos, para as mesmas são considerados delitos privados. Partindo de uma raiz elementar, pode-se afirmar que direito comunga com magia e religião, e as sanções legais estão referenciadas às sanções rituais. Assim, só se pode compreender o mecanismo do funcionamento do direito em sociedades primitivas à medida que se 
comparam sistemas inteiros de sanções sociais. Parece-me importante ressaltar que este autor nunca se desvencilhou completamente do evolucionismo, e apesar da ênfase sincrônica, sai de seu paradigma funcionalista para acolher o modelo evolucionista em determinados momentos de sua etnografia.

Segundo Kuper (1978) Radcliffe-Brown compartilhava o pensamento Roscoe Pound, o qual afirmava que o termo direito deveria ser usado somente quando fizesse referência ao controle social através da aplicação sistemática da força da sociedade politicamente organizada. Quando trabalha com as sociedades consideradas por ele primitivas, afirma que o termo direito só será empregado quando a sociedade analisada promover um uso coextensivo do direito com as sanções legais organizadas. As obrigações a serem obedecidas pelos membros de uma sociedade com ausência de sanções legais serão reconhecidas como costumes ou convenções. Neste último caso o termo direito fica fora de cogitação. Direito fica exclusivamente referido aos costumes apoiados em sanções, mesmo em sociedades que carecem de Estado.

É de destacar que, em todo esse período, a finalidade era identificar o que havia de diferente nas sociedades. Para Radcliffe-Brown, o Direito deveria ser analisado nas sociedades que possuíssem alguma forma reconhecida de governo. Por conseguinte, postulou que a sanção social se define como a atitude que os membros de uma sociedade adotam para demonstrar que um comportamento foi aprovado ou desaprovado. Ao trabalhar com as noções de aprovação e desaprovação, consequentemente trabalhou com as noções de positivo e negativo. Sendo assim, quando uma atitude é aprovada pela comunidade, pode-se afirmar que a sanção social aplicada foi positiva, uma vez que o comportamento em questão respondeu ao que deve ser feito. $O$ reconhecimento positivo pode se desdobrar no recebimento de títulos honoríficos, em fama e na boa relação com vizinhos, pois os mesmos tendem a tecer uma boa opinião a respeito do indivíduo.

O reconhecimento do caráter negativo de uma sanção se dá à medida que um comportamento é desaprovado. Uma sanção negativa pode ter caráter organizado ou difuso. Sendo assim, uma sanção organizada se traduz ao aplicar, aos sujeitos cujo comportamento foi desaprovado, procedimentos definidos, regulados e reconhecidos. Uma sanção difusa, por sua vez, concerne a procedimentos espontâneos e desorganizados. Radcliffe-Brown entendia que 
o Código Penal tribal estava constituído pelas sanções negativas organizadas; a lei foi delineada a partir da definição do jurista Roscoe Pound, como a forma que as sociedades politicamente organizadas encontram para aplicar, de forma sistemática, a força que mantêm o controle social. Para este autor, o que deve ser analisado pela Antropologia Jurídica é a forma como as sociedades politicamente organizadas administram as sanções, uma vez que este é o critério básico da lei e do direito tribal. Sendo que leis só podem ser detectadas em sociedades cuja organização política seja formal, culturas consideradas por este autor como mais primitivas sofriam pela falta de direito (Kuper, 1979).

Pospísil (1974), ao discorrer sobre a vingança, agrega o conceito de Radcliffe-Brown, a saber, que a mesma não deve ser considerada como uma forma legal ou de direito, mas não pelo aspecto funcional e sim pela latente carência de exercício de uma autoridade capacitada para deliberar sobre disputas. As sanções negativas difusas estão constituídas ainda por outras categorias. Como afirma Radcliffe-Brown, existem aquelas que estão impressas no escândalo, ou seja, aquelas que são expressas pela opinião pública da sociedade. Existem ainda sanções satíricas, as quais se definem pela ação de pessoas resolvidas a punir um transgressor através da exposição pública. Para tanto, preparam armadilhas que o conduzem à evidência. Há também sanções rituais, as quais podem ser resumidas como sanções negativas difusas, que causam grande impacto na comunidade por estarem referidas a crenças religiosas, acasos de bruxaria, sendo estes alvos de maior conflito dentro das sociedades por Radcliffe-Brown analisadas. Assim, quando há casos de feitiçaria, a reação dos vivos fica em segundo plano, uma vez que é das forças sobrenaturais que se espera sofrer as consequências previstas.

Ainda sobre sanções, Radcliffe-Brown as dividiu em primárias e secundárias, sendo que tal divisão compõe as sanções organizadas e as sanções difusas já citadas. As sanções primárias são aquelas referentes às ações da comunidade em geral ou de suas autoridades reconhecidas; ações secundárias, em contrapartida, se referem a uma ação particular, a uma ofensa privada que envolva grupos ou indivíduos oponentes.

A conceptualização das sanções é interessante para sinalizar de que forma se protegem direitos reconhecidos. Os termos sanções negativas difusas, sanções negativas organizadas, secundárias e primárias deixam claro quando 
este autor queria referir-se ao que considerava regras do costume ou regras legais. Haveria finalmente as definições de lex e jus formuladas por RadcliffeBrown. Assim, segundo Pospísil (1974), a definição de lex refere-se, por exemplo, ao imperativo de um soberano, à regras abstratas, que atuam dentro de um código legal ou de um estatuto. Lex portanto só existe em uma sociedade a medida em que esta é politicamente organizada e está baseada em códigos legais, tradicionais ou escritos, detentores de poder de coação. Em contrapartida, uma sociedade sem códigos ou regras abstratas não pode ser tomada como detentora de lei, ainda que nela existam costumes que sejam apoiados por sanções. Outra definição explorada por Radcliffe-Brown foi a de jus, a saber, categoria de onde deriva jurídico e justiça. A título de exemplo pode-se citar o jus gentium, categoria que se referia ao direito originado no costume, ao que concerne o Império Romano. Para se diferenciar lex e jus, é importante ter em mente categorias como coação ou compulsão, estando esta última relacionada à obrigatoriedade em responder aos imperativos da ordem pública.

Lex, isto é, as regras legais referem-se a uma autoridade legítima cuja obrigação é a de justamente formular e fazer cumprir a lei, no sentido de assegurar ordem e equidade nas relações sociais. Jus, por sua vez, diz respeito à obediência às regras do costume, a saber, que em cada sociedade humana cujos membros estejam conscientes dos direitos e deveres obrigados pelos costumes, se apresentará à categoria de jus. Assim, lex ou lei, e jus ou justiça possuem diferenças básicas, as quais, por vezes, se expressam no próprio significado das palavras.

\section{E. E. Evans Pritchard}

Em 1940 o antropólogo E. Evans-Pritchard publica Os Nuer. Este livro foi escrito e publicado em parte pela solicitação e consequente financiamento do governo do Sudão anglo-egípcio. As formas de subsistência e as instituições políticas dos nilota foram o foco da pesquisa empreendida. Pretendo utilizar somente a investigação sobre as instituições políticas, uma vez que é nelas que se encontra a discussão do autor em questão sobre o sistema legal do grupo estudado. 
A sistematização do campo da antropologia jurídica

Em uma definição inicial, Evans-Pritchard afirma que o conceito de estrutura política se refere aos relacionamentos, dentro de um sistema territorial, entre grupos de pessoas que vivem em áreas bem definidas espacialmente e que estão conscientes de sua identidade e exclusividade (Evans-Pritchard, 2002, p. 10). No sistema social Nuer, Evans-Pritchard se viu obrigado a enfrentar um problema complicado: por ser uma sociedade sem chefe, a análise da lei se complicava, uma vez que se tratava de uma sociedade aparentemente anárquica, ou melhor, uma sociedade desprovida de um Estado superior e um governo detentor da supremacia para estabelecer e manter a ordem social, ou mecanismos de coerção que a assegurassem.

Contudo, Evans-Pritchard argumentou contra este estado de anarquia, tentando esclarecer aspectos que jazem por trás dessa aparência. Argumenta, neste sentido, que o detectável são clãs acéfalos. Porém, a manutenção e o estabelecimento da ordem e das relações sociais sobre amplas áreas geográficas só pode ser alcançado através do estudo dos sistemas de parentesco. O sistema político Nuer, mesmo acéfalo ou não possuidor de chefes supremos, se dividia em segmentos de parentesco que se organizavam de forma de clãs. As relações eram estabelecidas a partir da divisão territorial e das relações entre linhagens, sendo que as mesmas eram reguladas a partir de um processo de divisão e fusão de linhagens maiores, médias e menores. Assim, nas palavras do autor: denominamos os segmentos maiores em que se divide um clã de linhagens máximas, os segmentos de uma linhagem maior de linhagens menores, e os segmentos de uma linhagem menor de linhagens mínimas (Evans-Pritchard, 2002, p. 11).

Para a manutenção do comportamento social, este sistema político se apoiava no respeito à estável instituição da vingança de sangue, instituição que mantinha um estado de animosidade constante entre dois grupos corporativos. Contudo, nem sempre um conflito resultava em homicídio ou pagamento da dívida de sangue. As vendetas constituem uma instituição tribal, pois podem ocorrer apenas quando se reconhece que houve uma infração à lei, já que constituem o modo pelo qual se obtém o ressarcimento. O temor de provocar uma vendeta é, com efeito, a mais importante sanção legal dentro de uma tribo e a principal garantia da vida e da propriedade de um indivíduo. Assim, segundo Evans-Pritchard um conflito de vingança só tem sentido à medida 
que existam relações sociais passíveis de rompimento e consequente restabelecimento, uma vez que as relações sociais necessitam ser eventualmente ajustadas, a não ser que tenham sofrido uma total ruptura (Evans-Pritchard, 2002, p. 162).

Quando um conflito que demanda vingança é mediado pelo pagamento de um preço de sangue, a violência que se estabelece entre os grupos tende a se amenizar. Se assim não ocorresse, os grupos sociais em pugna e mesmo o sistema social como um todo poderia ser seriamente afetado ou quiçá destruído pelos conflitos de vingança. O chefe-leopardo, ou Kuaarmuon, era a autoridade reconhecida para estabelecer a mediação. Era um líder religioso que arbitrava a respeito do preço de sangue a ser pago em uma disputa. O chefe-leopardo não era possuidor de nenhum poder jurídico ou coercitivo específico. Seus serviços eram demandados e obedecidos porque havia necessidade de uma mediação e porque as pessoas o respeitavam em seus serviços.

Além disso, havia necessidade de prevenção para possíveis conflitos de vingança no futuro. Estes aspectos da sociedade Nuer declaram que há lei e que há direito. Ambos operam no sentido de manter uma ordem e uma reciprocidade de obrigações e direitos, além de uma solidariedade social. Evans-Pritchard então argumenta que a manutenção do equilíbrio estrutural entre segmentos tribais opostos, os quais se encontram fundidos politicamente em relação às unidades sociais e geográficas maiores, só pode existir através da vingança. Interpreto que para Evans-Pritchard o direito é uma obrigação moral a ser cumprida se a intenção for a de resolver disputas por meios convencionais; contudo, este direito não pode ser entendido como procedimento ou instituição legal, como entendemos nas sociedades ocidentais. Este autor utiliza o termo lei civil somente porque toda afronta, ainda que seja a um assunto particular ou doméstico, é entendida como afronta ao bem comum, à coletividade, que coloca em risco a vida das pessoas. Tudo se transforma em direito civil porque é a própria comunidade que toma conta da infração na pessoa de seus membros afetados pela mesma. É a pessoa que denuncia e processa porque não existem autoridades. Não pode haver direito penal porque não há autoridades para denunciar e processar. 
A sistematização do campo da antropologia jurídica

Concluo então que o direito define-se, entre os Nuer, como uma certa classe de forças socialmente aprovadas para arbitrar sobre disputas. Sendo oposto ao direito ocidental, não prevalecem no direito Nuer, regras de conduta ou coerções sociais impostas por autoridades superiores. A lei entre os Nuer é operada com base na presença de regras particulares destinadas à manutenção de uma ordem aplicada por sanções particulares.

\section{Max Gluckman}

Na antropologia britânica, Max Gluckman se destacou por estabelecer, com grande rigor, uma discussão acerca do que caracteriza de fato uma lei. Para tal debate valeu-se das experiências recolhidas mediante a aplicação do método comparativo. Um dos problemas que Gluckman mais destacou dizia respeito à falta de estudos de leis que não fossem do universo ocidental; contestava ainda a imprecisão de qualquer língua vernácula. Argumentava que toda e qualquer palavra da língua inglesa que fosse destinada à designação de leis e fenômenos jurídicos em outras culturas já partiria carregada de significado, alguns por vezes ambíguos. Criticava os estudiosos das sociedades tribais por considerar que os mesmos iniciavam suas pesquisas cometendo erros, à medida que buscavam aplicar termos próprios às práticas de outras culturas. E afirmava que uma das palavras mais imprecisas semanticamente é lei.

Em seu livro The Judicial Process Among the Barotse of Northern Rhodesia de 1950, Gluckman analisou os juízes barotse empregando o mesmo olhar distanciado com que analisava os juízes dos Estados Unidos. Consequentemente, concluiu que os mecanismos de conduta judicial eram muito semelhantes. E essas semelhanças indicavam que quando havia uma regularidade de tarefas, as pessoas tendiam a utilizar as mesmas ferramentas. Em outras palavras, em qualquer sociedade humana, indivíduos com autoridade para deliberar acerca da quebra de uma norma de conduta ou acerca de um conflito, utilizarão ferramentas semelhantes para tratar infrações semelhantes, para auxiliar na decisão.

Existem dois conceitos que são recorrentemente trabalhados quando se pretende compreender como se sustenta a ordem social. A saber, o conceito de 
obrigação, referido ao pagamento ou restituição à pessoa afetada por aquela que lhe causou dano ou prejudicou; e o conceito de punição referido àquele que contravém a lei. Estes aspectos são importantes porque iluminam dicotomias como presença de cortes judiciais/ausência de cortes judiciais, restituição/castigo, entre outras. Alguns teóricos apostam no estudo de casos como o método que mais permite o uso de conceitos jurídicos para o desenvolvimento e aprimoramento de estudos e investigações. Assim, o caso pode ser considerado indispensável uma vez que representa o registro detalhado de uma disputa específica e de sua resolução, constituindo um universo privilegiado para a análise ${ }^{2}$.

\subsection{O corpus juris e a adjudicação}

Em seu livro sobre os Barotse, Max Gluckman (1967) trabalhou com acuidade a questão do direito tribal, dando ênfase à jurisprudência dos Lozi e formulando com isso novos conceitos para o estudo da Antropologia Jurídica. Segundo este autor, o Direito está presente nos usos e costumes e em instituições que se apresentam comuns às sociedades tradicionais, na justiça geral e no princípio de equidade e precedentes judiciais que são reconhecidas pelo povo Lozi e seus juízes. O direito, para este autor, implica o corpo total de

2 Segundo Gluckman, ao analisar o desenvolvimento do método de estudo de casos afirma que este se deu de forma autônoma, pois no começo os casos eram considerados como meras ilustrações, e não contextos para identificar costumes específicos, princípios de organização e relações sociais. Todavia, os casos considerados simples foram, mais tarde considerados úteis para estabelecer relações entre crenças e costumes envolvidas. A título de ilustração, cabe apontar o livro de Hoebel e Llewellyn, a saber, The Cheyenne Way, de 1941, como pioneiro do desenvolvimento dos casos problema - do inglês trouble-cases - ou seja, casos usados para o estudo das leis e dos costumes, antecipando a escola britânica em vários anos. Max Gluckman também analisou a questão dos casos problemas em seu livro sobre os Barotse. Contudo, Gluckman relata que, infelizmente, quando estabeleceu seu primeiro contato com este grupo, ainda não tinha o suporte que a Antropologia poderia oferecer, uma vez que a mesma, nesta época, não estava voltada para a análise dos casos, o que o fez tratá-los como se fossem meras ilustrações.

Latitude, Vol. 9, nº2, pp. 07-28, 2015 
A sistematização do campo da antropologia jurídica

regras, o que o torna detentor de variados significados. E tal aspecto se repete tanto no povo Lozi quanto nas sociedades ocidentais.

Gluckman marca a presença do legal que demarca os procedimentos que os tribunais Lozi deveriam seguir, as regras que deveriam aplicar, e as sanções que deveriam fazer cumprir. Dentro da nação em questão, o corpo total de leis, o qual foi reconhecido como costume por Gluckman, é denominado corpus juris e possui estatutos e regras. O corpus juris agrega tanto o conceito de lei (como lex) quanto o conceito de costume (como jus). O costume, portanto, produz as regras que orientarão a ação dos cutas (juízes) Lozi, e, portanto opera em todos os casos. Por mais que em muitos casos direito e costumes se apresentem como categorias indiferenciadas, Max Gluckman afirma que o costume é regular como a lei, sendo, entretanto, diferente da mesma por ser um outro fato social. De qualquer maneira, ambas são coletivas, exteriores ao indivíduo e possuem caráter coercitivo. A adjudicação, ou seja, o processo referente aos juízos a serem emitidos em relação aos casos, e a sua interação com o corpus juris são aspectos do conceito do direito em ação. Assim, este autor pôde concluir que a força da ação do direito reside na incerteza de seus conceitos básicos: os costumes por hora sustentando e por hora modificando o direito; a adjudicação trazendo à realidade o direito através de sua aplicação às diversas situações reais.

Para se ter uma ideia geral dos conceitos apontados e defendidos por Gluckman, lembremos que todas as sociedades possuem a justiça incorporada no conceito de corpus juris, para cumprir com o conjunto de regras obrigatórias. A mesma é utilizada pelas cortes ou tribunais para formular juízos no processo de adjudicação, o qual, por sua vez, só pode ser realizado a medida em que os juízes levarem em conta a lei - mais geral - como detentora do corpo de regras. Ao formular tais teorias, este autor escapa à possibilidade de optar pelo conceito de lei ou pelo conceito de costume, concentrando-se basicamente nos conceitos lex e jus ${ }^{3}$.

${ }^{3}$ Existe ainda o conceito de homem médio formulado por Gluckman: a categoria utilizada é reasonable man, o que literalmente deveria ser traduzido como homem razoável. Contudo, tal categoria, para o Direito no Brasil, se traduz como homem médio. Para se estabelecer uma comparação entre o comportamento de pessoas 
Sendo assim, a discussão sobre a adequação ou não dos termos do direito ocidental para as sociedades não ocidentais é contornada pela possibilidade de existirem dois conceitos cujos significados são mais abrangentes e, portanto menos específicos de uma determinada sociedade.

\section{Paul Bohannan e os sistemas folk}

Paul Bohannan, em seu livro Justice and Judgment Among the Tiv, de 1968, concluiu que aforma de atuar dos juízes Tiv era pouco semelhante à dos juízes ocidentais, uma vez que os primeiros tinham um raciocínio diferente e,

envolvidas em uma disputa, os juízes Lozi utilizam um conceito semelhante ao de homem médio. Este seria um protótipo a ser utilizado, pelos juízes, como norma comparativa de orientação judicial. Em outras palavras, o homem médio é aquele que se adapta razoavelmente às prescrições de sua posição social. Assim, em casos de disputa, os litigantes são tratados a partir de uma comparação estabelecida entre seu comportamento e o comportamento que se pressupõe que um homem médio teria. A expectativa de conduta de um homem médio conduz os juízes a se posicionarem de modo pertinente ao que concerne às ações das pessoas em disputa, afim de concluir se seus atos foram corretos ou equivocados. Segundo Pospísil (1974), Gluckman utilizou o conceito de homem médio por este estar presente universalmente, podendo ser detectado nos posicionamentos de quase todos os juízes, quando os mesmos necessitam deliberar acerca de casos de disputa ou conflitos e quando as regras de comportamento normativo são mais ou menos frágeis em sua aplicação. Ao mesmo tempo, Gluckman postulava que a ideia de homem médio deveria ser tratada pela Antropologia e pela Sociologia com o mesmo apreço com que são tratadas as noções de tipos ideais, de desvio e desviante, entre outros, no sentido de etnografar, registrar seus conteúdos de maneira similar para cada cultura. Ao analisar os Tiv, Bohannan reconheceu a noção de homem médio e afirmou que este conceito deve ser inferido, contudo somente de forma similar. Este conceito éútil para a análise na medida em que detecta a razoabilidade das ações de um homem, auxiliando o juiz Tiv a ponderar acerca da melhor maneira de conduzir um julgamento. Ou seja, não é uma categoria nativa, mas é uma noção que pode ser inferida, deduzida, ao se observar os procedimentos dos juízes. 
além disso, se valiam de conceitos culturais locais para avaliar os casos ou conflitos que se apresentavam. Ao debater com Gluckman, Bohannan se opunha à argumentação referente à possibilidade de aplicação dos conceitos analíticos ocidentais a contextos não-ocidentais.

Por mais que Gluckman criticasse a utilização de categorias do direito ocidental na análise de sistemas jurídicos não ocidentais, considerava que alguns desses conceitos poderiam auxiliar o esclarecimento de processos sociais que se assemelhassem. Outra crítica importante feita por Bohannan a Gluckman se referia à interpretação indevida dos conceitos barotse; segundo este autor, ao tentar acomodar conceitos não ocidentais em categorias da jurisprudência ocidental, o único que Gluckman conseguia era se afastar dos reais significados da jurisprudência nativa. Sendo assim, propôs um estudo aprofundado das línguas nativas, a fim de que as mesmas conduzissem aos sistemas folk de pensamento que orientassem a resolução de conflitos ${ }^{4}$.

No material que Gluckman adicionou na segundo edição de 1967 de seu livro O Processo Judicial entre os Barotse ele cita uma sentença da revisão de seu livro feita por Mary Douglas, a qual parece tocar o cerne do problema, uma vez que afirma a precisão existente em tal interposição de formas de pensamentos estrangeiros que reside no ato da interpretação. Grosso modo, isso sugere que é na justaposição das ideias previamente não conectadas que o ato

4 Vale lembrar que segundo Bohannan, um dos problemas mais recorrentes na Antropologia Social é o complexo papel de método comparativo na produção da etnografia. Este autor afirmava que diferentes opiniões sobre a natureza dos dados, sua organização dentro de uma etnografia e sua reorganização dentro dos estudos comparados tornavam os termos utilizados nas discussões muito díspares, e na Antropologia Jurídica essas diferenças assumiram importância maior. Bohannan afirmava que existem quatro importantes áreas que podem iluminar as análises, as quais são utilizadas em ordem crescente de importância: o uso de termos nativos para embasar uma etnografia; a referência ao sistema folk como contexto a partir do qual as ideias nativas obtêm seu sentido; alguns dos tipos de ginásticas intelectuais que têm sido chamadas comparação; e a diferença entre a teoria e a cultura da etnografia e a cultura da comparação. 
de interpretação pode ser encontrado. Com tal ideia na cabeça, a investigação de Bohannan lidou com quatro contextos nos quais novas justaposições puderam ser feitas e novos tipos de interpretações puderam ser justificáveis: as novas justaposições que aparecem quando um etnógrafo luta para apresentar suas ideias em sua língua materna a seus colegas; as novas justaposições enraizadas em modelos do etnógrafo e em modelos subjetivos de seu povo; a nova justaposição dos modelos etnográficos que aparecem quando vem de diferentes culturas; e a nova justaposição de novos modelos etnográficos os quais já foram aceitos como teoria.

Paul Bohannan discordando de Gluckman, desafiou seu sistema analítico a partir de sua investigação sistemática sobre os sistemas nativos de pensamento ou folk systems. Assim, Bohannan, em Justice and Judgmen tamong the Tiv, contribuiu para a metodologia investigativa da Antropologia Jurídica de sua época. Nesta publicação, Bohannan ponderou acerca da necessidade de se descrever o sistema legal de uma sociedade tradicional a partir dos próprios termos presentes nos sistemas folk. A comparação com o sistema moderno de controle jurídico ocidental lhe parecia cabível. Contudo, não se deveria tentar explicar os sistemas folk a partir de conceitos modernos ocidentais. Se assim se procedesse, se acarretariam imprecisões de tradução, além de confusões entre as teorias sociológicas e o método nativo em si. Analisar os sistemas de controle jurídico de sociedades tradicionais sem se valer da análise dos sistemas folk equivaleria a violentar as ideias particulares dos Tiv ou de qualquer outra sociedade ${ }^{5}$.

5 O debate entre Gluckman e Bohannan é peça crucial para a questão da comparação nos estudos especificamente antropológicos. O ponto nevrálgico mais evidente é o que concerne à utilização (ou ainda se a mesma é adequada) do aparato conceitual do Direito Ocidental na busca pela compreensão dos casos de disputa que se apresentam em sociedades consideradas tribais. A argumentação de Gluckman é que não se deve descartar a base teórico-metodológica oferecida pela Jurisprudência Ocidental, uma vez que a mesma seria excelente suporte lógico para o desenvolvimento da Antropologia Jurídica. Por outro lado, Bohannan discutia se a mesma utilização não conduziria a um etnocentrismo, o que, consequentemente, acarretaria uma abordagem pouco aprofundada e por isso quase inútil para a compreensão das práticas de resolução de conflitos nas sociedades não-ocidentais. Gluckman enfatiza a importância 
A sistematização do campo da antropologia jurídica

\section{Jane Collier e o desenvolvimento da antropologia jurídica nos Estados Unidos}

Analisando o colonialismo, Jane Collier (1995) entende que o debate entre Radcliffe-Brown e Malinowski se deu no contexto das necessidades dos administradores coloniais. Ora, os administradores oficiais das colônias, então encarregados da política do Indirect Rule (governo indireto), necessitavam enfrentar o problema de decidir quais costumes nativos eram normas jurídicas que deviam ser postas em vigor como obrigatórias para manter a ordem social e quais deviam ser suprimidas como contrárias à moral e à justiça europeias. Contudo este cenário mudou depois que a guerra acabou, iniciando-se um veloz processo de descolonização. Os administradores coloniais encontraramse então em uma situação de não ter mais voz ativa em relação às normas das sociedades não-ocidentais. Assim como os administradores coloniais, os parlamentares dos Estados-Nação recém constituídos, também se encontravam em uma posição de ter que desenvolver leis particulares.

Os Estados-Nação recém constituídos e suas elites governantes quiseram desenvolver uma codificação nacional única, que se aplicaria a todos

em identificar as semelhanças existentes entre o sistema europeu e o sistema africano; sendo que Bohannan, por sua vez, defende que os termos nativos devem ser compreendidos em si, e que os antropólogos não devem procurar uma tradução literal dos mesmos nas categorias jurídicas ocidentais. Indo mais além, este autor ainda defende que os sistemas sociais devem ser entendidos enquanto únicos, detentores de uma lógica própria, e somente compreensíveis e logo comparáveis interpelados a partir da lógica inerente ao sistema de pensamento de que fazem parte. Uma visão hermenêutica, como a postulada por Bohannan, impossibilitava um diálogo entre dois ou mais sistemas de direito. Em contrapartida, o posicionamento de Gluckman pode ser entendido como uma abertura para a interação de dois ou mais vocabulários do Direito. Em outras palavras, considerava que um vocabulário oriundo de um horizonte cultural particular, em poder do antropólogo, poderia ser usado como laço para captar os outros sistemas. 
os cidadãos e funcionariam todos os tribunais em uma só hierarquia. Não estavam interessados em conservar, e muito menos em fomentar e dar vigor aos diferentes costumes ou normas jurídicas de grupos étnicos subordinados. Jane Collier, instigada por Laura Nader, passou a pensar os processos de disputa para além do que havia sido proposto por Hoebel. A sugestão de Nader era a de utilizar nas análises dos processos de disputa tanto juízes quanto litigantes. Tal proposta a levou a desconsiderar o método de comparação de normas jurídicas postulado por Hoebel e adotar o método de comparação entre formas de manejar disputas.

Para obter os dados de análise, o proposto por Nader foi o registro de instâncias deagravo, o que permitiria uma melhor compreensão acerca das formas de compensação. Segundo a autora, a comparação entre processos de disputa auxiliava na descoberta de padrões alternativos a mão dos indivíduos opositores em um confronto; bem como na descoberta de padrões nos tipos de casos sobre os quais os juízes deviam tomar decisões. Contudo, é mister esclarecer o que são tais padrões alternativos de resolução de disputas para a autora: Sin embargo, pronto descubrí lo que, creo, la mayoria de los recolectores de casos descubren: que el proceso de disputa es mucho más revelador que los términos de acuerdos en los que Hoebel estaba interessado (Collier, 1995, p. 51). Os padrões recorrentes nos resultados dos casos se deviam às regularidades nos tipos de caso que chegavam as autoridades. As normas que prevaleciam nos casos de conflito se deviam às semelhanças nas restrições ou incentivos que moldavam as decisões dos disputantes em conflito.

As décadas de 60 e 70 nos Estados Unidos foram marcadas por uma forte tendência a desenvolver métodos alternativos de resolução de conflitos. O que logo foi seguido por uma mudança na análise dos processos de disputa, ou seja, a preocupação latente era por estudar a relação entre história, poder e sua influência no modelamento dos sistemas jurídicos. Nesta época alguns antropólogos passaram a usar o modelo social de conflito, se concentrando nos processos históricos particulares, responsáveis por dar forma às normas observadas. Os antropólogos que se interessavam pelas questões jurídicas começaram a tratar o direito como algo que advêm do conflito, buscando compreender os sistemas jurídicos não ocidentais através das lutas históricas pelo poder. 
A sistematização do campo da antropologia jurídica

Nesta data, os estudos históricos mais ricos sobre sistemas jurídicos nãoocidentaisvêm da África, talvez porque a descolonização converteu operíodo colonial em uma era histórica, campo de historiadores mais quede antropólogos sociais. Os primeiros enfatizam que o direito consuetudinário é uma criação colonial, que conduziu tanto a antropólogosquanto a historiadores a distinguir entre direito indígena, definido como o sistema jurídico pré-colonial agora perdido para além de qualquer recuperação, e o direito consuetudinário, definido como o produto de lutashistóricas de poder entre funcionários coloniais e povos colonizados. Os historiadores também revelaram que muitas das supostas normas tradicionais postas em vigor por tribunais consuetudinários, eram invenções recentes ou apropriações seletivas de costumes passados (Moore, 1989 apud. Collier 1995: 64).

Poder e história passaram então a ser o centro das preocupações, o que deixa transparecer uma mudança no campo teórico-metodológico da Antropologia Jurídica. Tal mudança contrastou com uma teoria consensual nos estudos antropológicos. Em outras palavras, os pesquisadores trabalhavam com as categorias de direito, controle social e processos de disputa como se as mesmas fossem ferramentas para a preservação da ordem social. Tais estudos estavam impregnados de uma suposição referente ao benefício generalizado advindo da preservação da ordem social, das normas e das leis.

\section{Clifford Geertz e o saber local}

Ao introduzir o oitavo ensaio intitulado O Saber Local: fatos e leis em uma perspectiva comparativa, de seu livro O Saber Local, de 1983, Clifford Geertz afirma que tanto a Antropologia quanto o Direito são disciplinas que devem ser analisadas como saberes locais. O Direito pode se valer de um caso 
individual afim de encontrar os mesmos pontos pertinentes de reflexão, enquanto a etnografia, ao analisar práticas locais estabelecidas, também detecta pontos de reflexão. Geertz reitera a semelhança entre Antropologia e Jurisprudência ao afirmar que a busca de fatos gerais a partir de fatos locais é comum a ambas. A semelhança dos procedimentos seguidos por antropólogos e juristas poderia sinalizar uma harmonia entre seus argumentos e ideias. Contudo, mesmo que ambos se interessem pelo individual e particular isso não significa que interajam com facilidade. Assim, seus interesses por assuntos específicos e práticos não os tornam pares. O que os distancia e separa é sua própria afinidade eletiva. Segundo Geertz, o debate mais recorrente dentro da Antropologia Legal ou Antropologia do Direito é aquele que pretende decifrar o que é o Direito.

Certamente a mais curiosa dessas curiosidades é o eterno debate sobre o conteúdo do direito; ou seja, se ele consiste de instituições ou regulamentos, de procedimentos ou de conceitos, de decisões ou de códigos, de processos ou de formas, e, portanto, se ele é uma categoria tal como o trabalho, que existe praticamente em qualquer parte do mundo onde nos deparemos com uma sociedade humana, ou algo assim como o contraponto, que certamente não é universal. (Geertz, 2004, p. 250).

No que se refere o Direito, os problemas relacionados entre as categorias que pertencem a uma cultura específica e as práticas localizadas em outras pode ser incômoda, pois se estabeleceu uma separação entre os aspectos lógicos e os aspectos práticos do direito, separação essa que atravanca o caminho, dificultando assim que a disciplina tenha êxito em seus objetivos. Apesar das semelhanças nos interesses pelo prático, pelo específico, e apesar da utilização de técnicas especiais, Direito e Antropologia não interagem de forma harmoniosa, mas sim de forma hesitante e ambivalente. 
A sistematização do campo da antropologia jurídica

E, ao invés de termos uma penetração da sensibilidade jurídica na antropologia, ou da sensibilidade etnográfica no direito, o que vemos é um conjunto limitado de debates estáticos, em que se tenta descobrir se os conceitos da jurisprudência ocidental têm alguma aplicação útil em contextos não-ocidentais, ou se o estudo do direito comparativo consiste em saber como os africanos ou os esquimós concebem a justiça, ou como são resolvidas as disputas na Turquia ou no México; ou ainda se os regulamentos jurídicos realmente restringem o comportamento ou unicamente servem como justificativas racionais para encobrir aquilo que algum juiz, advogado, litigante ou qualquer outro maquinador semelhante queria fazer, de qualquer maneira. (Geertz, 2004, p. 251).

A Antropologia Jurídica possui grandes títulos acerca da análise do controle social em sociedades tribais, tais como Gluckman, Malinowski, Bohannan, entre outros, e atualmente segue-se produzindo análises semelhantes com conceitos similares. Contudo, a pretensão de Geertz, antes de criticar ou desconsiderar tais estudos, é a de afastar-se dos mesmos. O autor pretende distanciar-se deles uma vez que entende que antropólogos e juristas se detêm na busca de algo útil na outra parte, ou seja, antropólogos se arrogam em encontrar utilidade no Direito, e o contrário também se dá. Esse procedimento se estabelece à medida que ambos buscam auxílio para a resolução de seus problemas clássicos. Ora, ao dividir assim Antropologia e Direito, o único que se consegue é a criação de uma disciplina centauro; o que Geertz argumenta é que ambos deveriam compreender os significados da outra disciplina em sua totalidade. Para tanto, a tarefa deve ser a de encontrar temas específicos de análise que sejam compartilhados.

(...) não um esforço para impregnar costumes sociais com significados jurídicos, nem para corrigir raciocínios jurídicos através de descobertas 
antropológicas, e sim um ir e vir hermenêutico entre os dois campos, olhando primeiramente em uma direção, depois na outra, a fim de formular as questões morais, políticas e intelectuais que são importantes para ambos. (Geertz, 2004, p. 253).

Esse autor defende que o Direito é saber local. E este termo local referese, para além do contexto de lugar e época, ao complexo de caracterizações e suposições, ocorrências reais manifestas em princípios abstratos, o que Geertz denomina sensibilidade jurídica. O Direito, trocando em miúdos, é saber local que constrói a vida social. Essa aposta de Geertz o leva ao desenvolvimento de uma metodologia para um estudo comparativo, metodologia esta considerada pelo próprio autor como pouco ortodoxa, a saber, a tradução cultural. Seu exercício é o da comparação, no sentido de buscar a formulação de características referentes a uma sensibilidade jurídica, as quais respondam em termos das pressuposições, preocupações e estruturas de ação características de outra sensibilidade jurídica.

O saber local, o Anschauung e o caso imediato, a visão do direito; a desagregação do direito e da antropologia como disciplinas a fim de estabelecer a conexão entre elas através de interseções específicas e não de fusões híbridas; a relativização da oposição leis/fatos, em um jogo variado de imagens coerentes e fórmulas conseqüentes; a concepção do estudo comparativo do direito como um exercício de tradução intercultural; a noção de que o pensamento jurídico é construtivo de realidades sociais e não um mero reflexo dessas realidades; a ênfase na tenacidade histórica das sensibilidades jurídicas, a rejeição de uma visão segundo a qual o poder prático do direito resulta do consenso social, a favor de uma que busca significados; a convicção de que o pluralismo jurídico não é uma aberração temporária e sim um elemento central no 
A sistematização do campo da antropologia jurídica

cenário moderno; e o argumento que o autoentendimento e o entendimento do outro estão tão internamente conectados no direito, como o estão nos outros domínios da cultura - todos esses são produtos de uma certa forma de pensar, uma forma de pensar que se extasia com a diversidade das coisas. Juntos, esses argumentos não se combinam, necessariamente, para formar uma posição sistemática, um "hermeneuticismo" ou algum outro termo igualmente absurdo; melhor dito, eles impulsionam uns aos outros, se é que podemos dizer que temas são capazes de fazer tal coisa, e de fazê-la com a regularidade suficiente para sugerir que - embora não haja dúvida de que seria demasiada pretensão modificar os versos de Shelley e proclamar os advogados os esquecidos poetas do mundo - conceber o direito como uma espécie de imaginação social pode ter algum valor. (Geertz, 2004, p. 352).

Sendo assim, concluo afirmando que a proposta de Geertz parte da limitação da comparação da tradução cultural para encontrar as situações em seus contextos. Tomando livremente as palavras do autor, afirmo que o que pretende é realizar uma descrição densa das sensibilidades jurídicas.

\section{Conclusão}

Ao pensar sobre os caminhos percorridos tanto pela Antropologia quanto pelo Direito, concluo que a primeira se voltou ao estudo das sociedades não-ocidentais, enquanto a segunda surgiu e se estabeleceu dentro de uma perspectiva mais centralizada nas tradições ocidentais. Assim, sugiro que a perspectiva etnocêntrica, a qual é rechaçada por grande parte dos antropólogos, muitas vezes configura-se praxe legítima dos juristas.

Em contrapartida, atualmente se pensa que os processos jurídicos e as instituições beneficiam mais a uns que a outros. As classes governantes são 
tratadas como responsáveis pela manutenção das normas e leis, as quais, contrariamente, deveriam ser vistas como acessíveis e benéficas a todos. Enfocan la forma en que las elites usan los procesos de control para manejar a las clases bajas y evitar que los oprimidos se subleven, en vez de tratar los procesos de control social como limitantes de desviaciones. (Collier, 1995, p. 65).

Uma vez que se transformam as teorias, Collier afirma que se deveriam mudar as metodologias. Assim, se o direito é encarado como uma categoria dominante na ordem social, ele deve ser analisado conjuntamente a outros mecanismos de dominação, ou seja, elementos que compõem uma estrutura social tais como economia, parentesco, processos políticos e religiosos. A conjunção de tais aspectos abre caminho para a compreensão da ação do poder em relação às normas, as incidências de conflito e o processo de disputa.

Os aspectos teóricos mais relevantes do desenvolvimento do campo da Antropologia Jurídica nos dá uma ideia da amplitude desta disciplina. O histórico que realizei iluminou aspectos da formação da disciplina; entre eles podem ser citados os estudos do direito considerado primitivo, as relações entre os estudos da Antropologia e do Direito, as diferenças detectadas entre o direito das sociedades tradicionais e das sociedades modernas, o costume como fonte do direito positivo e práticas teórico-metodológicas do estudo comparativo.

Atualmente, o estudo da Antropologia Jurídica nos auxilia a entender questões pertinentes, por exemplo, ao Pluralismo Jurídico, às características etnocêntricas do Direito - como o universalismo e o evolucionismo - versus diferentes debates atuais da Antropologia; auxilia ainda na compreensão dos conceitos de direito consuetudinário e povos indígenas na América Latina, o que abarca questões referentes ao direito oficial estatal em contraposição aos sistemas jurídicos destes povos.

Entendo que a ênfase dada às regras consuetudinárias estreita as possibilidades de análise, pois descarta aspectos importantes que operam para a manutenção do controle social. Assim, afirmo que para a realização de uma análise que cumpra com a missão de esmiuçar os aspectos de controle social, o direito deve ser considerado como conceito, fenômeno e instituição.

Finalmente podemos ver que todos estes estudos na Antropologia Jurídica podem ser classificados em duas categorias principais: (1) o 
A sistematização do campo da antropologia jurídica

conhecimento da ordem social, e (2) o conhecimento da interação social. A saber, o primeiro se refere ao significado das normas e regras (o direito e a ordem) que implicam os conceitos desejáveis que "deveriam" dirigira vida social, enquanto que o segundo se refere ao conhecimento da interação social como categorias que se referem ao que realmente ocorre às sociedades tradicionais. Estas categorias dicotômicas foram desenvolvidas ao mesmo tempo. Por outro lado, todas estas categorias e conceitos usados para estudar sociedades tradicionais são colocados à prova quando tem que servir para analisar os choques entre os direitos consuetudinários e as regras legais positivas.

Finalmente, o campo da Antropologia Jurídica e seus pesquisadores têm o desafio, primeiramente, de trabalhar com a noção de mudança, entendendo que as categorias não ocidentais de direito e costume não são estagnadas; não estão cristalizadas no tempo. Em oposição a isso, elas são cambiantes e passíveis de agregar conhecimentos e informações.

\section{Referências:}

BOHANNAN, Paul, 1968. Justice and Judgment amog the TIV. London: Oxford University Press.

COLLIER, Jane F. 1995. Problemas teórico-metodológicos en la antropología jurídica. In: CHENAUT, Victoria y María Teresa Sierra (Orgs.). Pueblos indígenas antes el derecho, México: CIESAS, p. 45-78.

DURKHEIM, Émile, 1995. Da Divisão do Trabalho Social. São Paulo: Editora Martins Fontes.

EVANS-PRITCHARD, E. 2002. Os Nuer. São Paulo: Editora Perspectiva.

GEERTZ, C. 2004. O saber local: novos ensaios em antropologia interpretativa. Petrópolis, Editora Vozes.

GLUCKMAN, M. 1967. The Judicial Process among the Barotse of Northern Rhodesia. London: Manchester University Press.

HOEBEL, E. A. 1967. The Law of Primitive Man. Cambridge, Massachusetts: Harvard University Press. 
KUPER, Adam, 1978. Radcliffe-Brown. In: Antropólogos e Antropologia. Rio de Janeiro: Francisco Alves.

MALINOWSKI, B. 2003. Crime e Costume na Sociedade Selvagem. Brasília: Editora Universidade de Brasília, UnB.

NADER, L. 1997. Law in Culture and Society. California: University of California Press Berkeley and Los Angeles.

POSPÍSIL, L. 1974. Anthropology of Law: A comparative theory. HRAF. Press New Haven.

RADCLIFFE-BROWN, A. 1973. Estrutura e Função na Sociedade Primitiva. Petrópolis: Editora Vozes. 